\title{
ESCOLA E DIDÁTICA DESENVOLVIMENTAL: SEU CAMPO CONCEITUAL NA TRADIÇÃO DA TEORIA HISTÓRICO-CULTURAL ${ }^{1}$
}

Roberto Valdés Puentes* Andréa Maturano Longarezi**

RESUMO: O artigo discute, sob a base da filosofia marxista e da psicologia histórico-cultural, escola e didática, numa perspectiva que tem no desenvolvimento integral do estudante sua tese fundamental. $\mathrm{O}$ texto percorre conceitos que, em sua globalidade, estabelecem os princípios que norteiam essa concepção de educação e de ensino, baseada na formação do pensamento teórico: educação, escola, desenvolvimento, pensamento teórico, didática desenvolvimental, atividade de ensino e aprendizagem, entre outros. Fundamenta o campo conceitual da escola e da didática desenvolvimental, a partir da sistematização e análise desses conceitos e das relações a eles intrínsecas. Esse constructo permite afirmar que a didática desenvolvimental tem o ensino intencional como seu objeto, a aprendizagem como condição e o desenvolvimento das neoformações e da personalidade integral do estudante como objetivo. Sob esse enfoque, depreende-se, pois, que a didática se projeta e se efetiva na relação indissociável ensino-aprendizagem-desenvolvimento.

Palavras-chave: Escola; Didática Desenvolvimental; Formação do Pensamento Teórico; Teoria da Atividade; Psicologia Histórico-cultural.

\footnotetext{
*Doutor em Educação (UNIMEP); Docente do PPGED/FACED/UFU; Pesquisador PPM/FAPEMIG. Área de pesquisa: didática e formação de professores. E-mail: robertopuentes@faced.ufu

* *Doutora em Educação Escolar (UNESP); Docente do PPGED/FACED/UFU; Pesquisadora PPM/FAPEMIG; Consultora ad hoc do CNPq; Área de pesquisa: didática, processos de ensino-aprendizagem e formação de professores. E-mail: andrea@faced.ufu.br
} 


\section{SCHOOL AND DEVELOPMENTAL DIDACTICS: ITS CONCEPTUAL FIELD IN THE CULTURAL- HISTORICAL THEORY}

ABSTRACT: This paper studies school and didactics under the fundamental thesis of the integral development of the student, based on the Marxist philosophy and cultural-historical psychology. The text discourses concepts that, in its totality, establish the principles that guide this conception of education and teaching, based on the formation of theoretical thinking: education, school, development, theoretical thinking, developmental didactics, teaching and learning activity, among others. It bases the conceptual field of school and developmental didactics on the systematization and analysis of these concepts and the relationships within them. This construct allows for the confirmation that developmental didactics holds intentional teaching as its object, learning as its condition, and development of neoformations and student whole personality as its goals. Under this approach, it is possible to infer that didactics can be projected and carried out on the inseparable relation of teaching/learning/development.

Keywords: School; Developmental Didactics; Formation of Theoretical Thinking; Activity Theory; Cultural-historical Psychology.

\section{INTRODUC̣ÃO}

A constituição do Estado soviético marca o início da tradição marxista da educação. Nesse contexto surge pela primeira vez a necessidade de redefinir o papel da educação, da escola, bem como da ciência pedagógica e da didática a serviço da construção de uma sociedade socialista.

Desde então, o processo de formação e desenvolvimento da pedagogia transcorreu sob a influência das ideias marxista-leninistas, com a participação inicial e mais próxima de V. I. Lenin, M. I. Kalinin, M. N. Petrovski, N. K. Krupskaia, A. S. Makárenko, entre outros teóricos; e, depois, dos representantes da chamada teoria psicológica histórico-cultural, entre os quais se destacam alguns dos membros da primeira, segunda e terceira geração, tais como L. S. Vygotsky, A. N. Leontiev, A. R. Lúria, D. B. Elkonin, A. V. Zaporozhets, P. Ya. Galperin, V. V. Davídov, L. V. Zankov, N. F. Talizina, V. S. Mujina, L. I. Bozhovich, A. Petrovski e P. I. Zinchenko.

Todos esses intelectuais contribuíram na criação das bases psicológicas e pedagógicas da nova teoria e prática da educação marxista, bem como da nova escola e da nova pedagogia. Foram elaboradas e estabelecidas as teses fundamentais sobre o papel da educação na criação das condições necessárias para o surgimento da consciência do homem, no 
processo de formação do pensamento e da linguagem, no desenvolvimento histórico-social do homem e no problema da apropriação pelo homem da experiência histórico-social etc.

Tomando esse contexto e sob a base da filosofia marxista e da psicologia histórico-cultural, o artigo discute escola e didática numa perspectiva que tem no desenvolvimento integral do estudante sua tese fundamental. Para isso, o texto percorre conceitos que, em sua globalidade, estabelecem os princípios que norteiam essa concepção de educação e de ensino, baseada na formação do pensamento teórico: educação, escola, desenvolvimento, pensamento teórico, didática desenvolvimental, atividade de ensino e aprendizagem, entre outros. Nesse sentido, fundamenta o campo conceitual da escola e da didática desenvolvimental, a partir da sistematização e análise desses conceitos e das relações a eles intrínsecas, tomando como referência diferentes autores russos que elaboram as bases de uma teoria psicológica e pedagógica de cunho marxista.

\section{A NATUREZA SÓCIO-HISTÓRICA DA CONSCIÊNCIA}

Sob esse constructo, o primeiro aspecto que precisa ser destacado é a natureza sócio-histórica do homem. A teoria histórico-cultural estabeleceu a tese fundamental sobre o caráter social e racional da natureza humana. Segundo Vygotsky (1956), o desenvolvimento da psique no indivíduo é de natureza social e tem lugar por intermédio do processo de interiorização, de transformação do interpsíquico (atividade coletiva) em intrapsíquico (atividades individuais). A tese ficou registrada com a seguinte frase: "A fonte da evolução histórica da conduta não há que busca-la no interior do homem, mas fora dele, no meio social ao qual pertence [...]" (VYGOTSKI, 1956, p. 449). A partir de então passou-se a considerar que as aptidões e caracteres especificamente humanos não se transmitem de maneira hereditária, mas se adquirem pela via da apropriação da cultura criada pelas gerações precedentes. A esse respeito Leontiev (1903-1979) iria afirmar:

Podemos dizer que cada indivíduo aprende a ser um homem. O que a natureza lhe dá quando nasce não lhe basta para viver em sociedade. É-lhe ainda preciso adquirir o que foi alcançado no decurso do desenvolvimento histórico da sociedade humana. (LEONTIEV, 1978, p. 265). 
O desenvolvimento da consciência enquanto forma superior de manifestação da psique é, nesse sentido, uma atividade real que relaciona o sujeito com a realidade. O conteúdo da consciência (imagem mental) é, portanto, produzido dialeticamente pela atividade humana por meio da qual torna-se possível transformar o objetivo em subjetivo, isto significa que

[...] qualquer objeto vai aparecer em primeiro lugar de maneira objetiva, nas relações objetivas do mundo objetal; que, em segundo lugar, vai supor a existência de uma sensibilidade subjetiva do homem e também da consciência humana (em suas formas ideais) [...] (LEONTIEV, 2004, p. 50).

Depois de internalizado o objeto, ele pode ser transmitido, em toda a sua riqueza, pela linguagem, tornando-se um conteúdo socialmente disponível. Neste sentido, “[...] a comunicação [...] constitui, portanto, a segunda condição inevitável do processo de assimilação pelos indivíduos dos progressos do desenvolvimento sócio-histórico da humanidade [...]” (LEONTIEV, 1978, p. 238), sendo a atividade a primeira.

Os clássicos trabalhos de Leontiev, O desenvolvimento do psiquismo (1978) e Actividad, conciencia e personalidad (1983), bem como Linguagem, desenvolvimento e aprendizagem de Vygotsky, Luria e Leontiev (1981), trazem para discussão a formação do psiquismo humano e a íntima relação entre a estrutura objetiva da atividade humana e a estrutura subjetiva da consciência. Leontiev (1978) considera que essa formação é complexa por situar-se na inter-relação indivíduo-sociedade [...] (FRANCO; LONGAREZI, 2011, p. 568).

A consciência individual desenvolve-se por meio da consciência social e os significados, elaborados na prática social, desempenham um importante papel nesse processo: “[...] no momento em que eu percebo um objeto, não só estou percebendo suas dimensões espaciais e temporais, como também percebo o seu significado [...]" (LEONTIEV, 2004, p. 51). Portanto, por meio da atividade, o homem domina o uso de instrumentos materiais, bem como, e de maneira análoga, domina um sistema de significações que já encontra pronto, formado historicamente.

[...] a significação é refletida e fixada na linguagem [...]. Sob a forma de significações linguísticas, constitui o conteúdo da consciência social; entrando no conteúdo da consciência social, torna-se assim a 'consciência real' dos indivíduos, objetivando em si o sentido subjetivo que o refletido tem para eles. 
Assim, o reflexo consciente é psicologicamente caracterizado pela presença de uma relação interna específica, a relação entre sentido subjetivo e significação [...] (LEONTIEV, 1978, p. 94).

Leontiev (1983, p. 07) ressalta ainda que "[...] a consciência deve ser considerada não como um espaço contemplado pelo sujeito no qual suas imagens e conceitos são projetados, mas como um movimento interno específico gerado pelo movimento da atividade humana."

\section{EDUCAÇÃO, ESCOLA E ENSINO PARA O DESENVOLVIMENTO}

Dentro da tradição marxista e histórico-cultural, foi atribuída à educação a responsabilidade de oferecer as condições para que o homem efetue a apropriação da cultura criada pela humanidade ou pelas gerações precedentes, em cujo processo ele elabora também sua própria humanidade, desenvolve sua própria consciência, pois não se nasce humano, o humano se constrói. Em outras palavras, deve ser responsabilidade da educação propiciar a condição biossocial, por meio da produção de ideias, conceitos, valores, símbolos, hábitos, atitudes, habilidades que são necessários - junto com os bens materiais - para dominar a realidade e transformá-la.

Ao produzir saber científico e sistematizado, o homem cria também as condições básicas para a sua inserção na sociedade, com a qual garante não apenas a própria sobrevivência, como indivíduo singular que é, mas também perpetua o futuro da humanidade. A existência mesma do homem como ser social, dotado de uma psique humana, tem uma origem e uma mediação social e histórica. É por intermédio da educação, entendida em sua mais ampla acepção como a transmissão da cultura de uma a outra geração, que o indivíduo entra em contato com a experiência humana e dela se apropria. Precisamente, o processo de apropriação constitui a forma exclusivamente humana de aprendizagem. Enfim, a educação é a ferramenta social pela qual os indivíduos são inseridos, mergulhados, imersos na sua cultura.

Só um sólido sistema educacional, pautado em princípios verdadeiramente democráticos que garantam a todos os cidadãos a possiblidade de adquirir instrução, pode estabelecer e realizar uma educação dessa natureza. A escola é o componente fundamental desse sistema educacional da tradição marxista e da teoria histórico-cultural. A ela cabe a responsabilidade de 
encaminhar os esforços para a formação do interesse ativo e efetivo pelos conhecimentos, que constituem a base do desenvolvimento integral dos estudantes. A escola é a instituição socialmente criada como espaço de humanização e desenvolvimento do homem, pela via da experimentação de mudanças qualitativas na sua vida psíquica, mediante as novas formações (linguagem, percepção, representação, imaginação, memória lógica, atenção, concentração, raciocínio lógico, pensamento teórico, resolução de problemas etc.) constituídas nos processos de ensino-aprendizagem.

Desenvolvimento, na perspectiva da psicologia marxista,

[...] se caracteriza, antes que nada, pelas formações novas, isto é, pelas mudanças qualitativas na vida psíquica do homem [...]. O desenvolvimento intelectual [especificamente] se dá em consonância com duas linhas: 1) o desenvolvimento funcional do intelecto, que consiste no enriquecimento do conteúdo por intermédio das ações intelectuais e conceitos novos; 2) o desenvolvimento por estágios (por idade) que se caracteriza pelas mudanças qualitativas no intelecto e sua reestruturação [...]. É importante afirmar que as duas linhas indicadas do desenvolvimento intelectual se inter-relacionam [...] (TALIZÍNA, 2000, p. 305).

A teoria marxista-leninista considera a personalidade um fenômeno complexo da vida social, não separado dela, não imutável e que se desenvolve a par dela, no processo da atividade socioprodutiva. Petrovski (1986) define a personalidade como:

O homem liberado do mundo animal como resultado do trabalho se desenvolve dentro da sociedade e entra em contato contínuo com outras pessoas, convertendo-se, assim, com ajuda da linguagem, em pessoa ou sujeito do conhecimento e da ativa transformação da realidade [...] (p. 88).

A instituição socialmente responsável por intervir de maneira positiva em todos os aspectos da vida psíquica do estudante, desenvolvendo em especial suas capacidades mentais e sua personalidade é a escola. Não obstante, ainda quando a escola deve participar - e participa - no processo de formação multifacetária dos estudantes, a formação do pensamento teórico ocupa um lugar central no desenvolvimento. Esse tipo de pensamento ocupa tal posição sobretudo no nível fundamental (entre os 6 e os 9 anos), quando a atividade condutora ou principal do desenvolvimento psíquico da criança é a aprendizagem, o que não invalida a função e a importância 
do pensamento empírico na formação dela e nem ignora suas limitações dadas certas condições. Talizina (2000) reconhece, com base nas ideias de Vygotsky e Elkonin, que é justamente o desenvolvimento do pensamento teórico que favorece nesse período o processo de formação de outras funções mentais, em especial os da percepção e da memória.

De acordo com Davídov (1988), pensar significa inventar, construir na mente o projeto idealizado (correspondente à finalidade da atividade, a sua ideia) do objeto real que deve ser o resultado do processo laboral pressuposto. Isto é:

Pensar significa transformar, em correspondência com o projeto ideal e o esquema idealizado da atividade, a imagem inicial do objeto de trabalho em outro objeto idealizado [...] (DAVÍDOV, 1988, p. 124).

O pensamento teórico, particularmente, é visto como um tipo especial de capacidade mental superior com características e especificidades que só podem ser desenvolvidas no espaço da escola. Constitui também o produto superior da matéria especificamente organizada na forma de imagem ideal do mundo objetivo, é a atividade espiritual como reflexo ideal da atividade objetal; A definição que o próprio Davídov (1988) faz de pensamento teórico é clara:

O conteúdo do pensamento teórico é a existência mediatizada, refletida, essencial. O pensamento teórico é o processo de idealização de um dos aspectos da atividade objetal prática, a reprodução, nela, das formas universais das coisas [...] (p. 125).

Nessa perspectiva, pensamento teórico é, portanto, entendido como:

[...] o processo ativo de reflexo objetivo em conceitos, juízos, teorias, etc. [...] é o processo psíquico socialmente condicionado de busca e descoberta do essencialmente novo e está indissoluvelmente ligado à linguagem [...] (PETROVSKI, 1986, p. 292).

O pensamento teórico possui algumas particularidades, tais como: 1) o objeto do conhecimento é colocado mentalmente em condições nas quais sua essência pode ser posta à vista com objetividade; 2) a realidade se modifica em objeto das posteriores transformações mentais; 3) no experimento dado se forma um sistema de conexões mentais dentro do qual é situado o objeto (BÍBLER, 1969 apud DAVÍDOV, 1988, p. 125). 
O desenvolvimento do pensamento teórico ocorre sob a base da formação de conceitos científicos e de ações mentais psicológicas, lógicas e específicas, de modo que formar o pensamento teórico implica formar conceitos e ações mentais.

Segundo Galperin (2001), o conceito é a imagem do objeto em seus traços essenciais. A imagem se forma sob a base da ação com o objeto, como seu reflexo. Assim, os conceitos científicos se caracterizam por constituírem os elementos essenciais da experiência social, as conquistas das gerações anteriores, na forma de imagens abstratas e generalizadas, que os alunos assimilam convertendo-as em experiência individual própria e em elementos de seu desenvolvimento intelectual.

O conceito é a forma de atividade mental por intermédio da qual se reproduz o objeto idealizado e o sistema de suas relações, que em sua unidade refletem a universalidade ou a essência do movimento do objeto material. O conceito atua, simultaneamente, como forma de reflexo do objeto material e como meio de sua representação mental, de sua estruturação, isto é, como ação mental especial.

[...] Ter um conceito sobre um ou outro objeto significa saber reproduzir mentalmente seu conteúdo, construí-lo. A ação de construção e transformação do objeto mental constitui o ato de sua compreensão e explicação, o descobrimento de sua essência [...] (DAVÍDOV, 1988, p. 126).

Importa ressaltar que na tradição da teoria histórico-cultural, diferentemente de outras concepções, o conceito exprime a compreensão do pensamento lógico-teórico como reflexo subjetivo do mundo material. Talizina (2000) também contribui no estudo do tema, sobretudo com a definição e análise dos conceitos matemáticos. Segundo a autora, o conteúdo do conceito " [...] compreende aquele sistema de características essenciais sobre cuja base surge a união dos objetos dados de uma classe [...]" (p. 23). Além disso, divide os conceitos em dois grupos diferentes: 1) os conceitos absolutos, que unem os objetos em classes específicas conforme características determinadas, as quais indicam a essência desses objetos; 2) os conceitos relativos, que unem os objetos em classes específicas por meio das características que indicam sua relação com outros objetos.

A definição, o conteúdo e as etapas na formação das ações mentais (habilidades), por sua vez, têm sido objeto de estudo de muitos 
representantes da teoria histórico-cultural. Não obstante, talvez tenha sido primeiro Galperin e depois Talizina os dois teóricos russos que mais tempo e esforços destinaram à compreensão das ações mentais. Galperin, num texto que data de 1959, destinado ao estudo sobre a formação dos conceitos e das ações mentais (GALPERIN, 2001, p. 45), vai afirmar:

Toda ação se caracteriza ante tudo pelas variações que produz em seu objeto e pelo resultado a que conduz. Igualmente, a ação mental se caracteriza por sua variação determinada e por seu caráter dirigido a um fim de seu objeto. Mas aqui o objeto é "mental". Por isso a ação mental se pode determinar como a habilidade de realizar "mentalmente" uma transformação determinada do objeto.

A formação dos conceitos e das habilidades tem lugar ao mesmo tempo e não da maneira como a pedagogia tradicional costuma sugerir que acontece: primeiro, os estudantes apropriam-se formalmente do conceito como produto pronto e acabado, depois desenvolvem as ações mentais que permitem sua aplicação. A tradição da teoria histórico-cultural reforça a ideia de que produzir conceitos significa produzir conhecimentos científicos em unidade com as ações mentais (análise, síntese, abstração, generalização) que constituem a base dos conceitos produzidos. Em outras palavras, os conceitos, enquanto formas de atividade mental, por intermédio da qual se reproduz o objeto idealizado e o sistema de suas relações, dependem da habilidade de realizar "mentalmente" uma transformação determinada desse objeto. Enfim, apropriar-se do conceito de um objeto implica executar uma determinada ação encaminhada à "transformação" do objeto, mas não necessariamente à "transformação" de sua natureza interna mas sim de sua modificação de objeto desconhecido em objeto conhecido; isto é, de objeto em si, a objeto para si. Junto com a transformação do objeto do conhecimento, o sujeito se transforma a si mesmo produzindo modificações significativas no seu desenvolvimento, seja no plano funcional (quantitativo) seja no evolutivo (formação de um nível psicofisiológico novo).

Para Leontiev, "[...] a atividade conceitual na criança não surge porque ela domina o conceito, mas, pelo contrário, domina o conceito porque aprende a agir conceitualmente, ou seja, a prática é conceitual [...]" (NUNEZ, 2009, p. 69). 
$\mathrm{Na}$ perspectiva aqui em discussão, a principal característica do processo de apropriação ou de "aquisição" do conhecimento teórico é, portanto, a criação no homem de aptidões novas, funções psíquicas novas, sob a base da atividade conceitual. É isso que o diferencia do processo de aprendizagem dos animais. Enquanto esse último é resultado de uma adaptação individual do comportamento genérico a condições de existência complexas e mutantes, a assimilação no homem é um processo de reprodução, nas propriedades do indivíduo, das propriedades e aptidões historicamente formadas da espécie humana (LEONTIEV, 1978, p. 270).

Sobre o processo de interação no qual se dá a formação dos conceitos e das ações mentais, Galperin (2001) vai afirmar:

[...] no processo de aprendizagem do conceito, a imagem abstrata do fenômeno se constitui sobre a base da ação nos componentes deste conceito, com o critério dos fenômenos correspondentes. O curso automatizado desta ação generalizada, abreviada e trasladada ao plano mental constitui o mecanismo psicológico do conceito [...] (p. 54).

Assim, a formação do conceito não se efetiva pela assimilação de seu conteúdo, mas pela aplicação dos signos, tendo em vista verificar se há no material o fenômeno que reflete o conceito. Por último é importante afirmar que novas ações e novos conceitos são adquiridos pela interação com os objetos a eles relacionados, mediatizados por conceitos e ações previamente adquiridos ou pela atividade material e psíquica.

Muitas coisas ainda faltam ser esclarecidas dentro da teoria histórico-cultural no que tange à correlação entre os componentes do conceito e o conceito mesmo, entre a imagem e a ação, entre o processo de assimilação do conceito e sua formação.

\section{DIDÁTICA DESENVOLVIMENTAL: ATIVIDADES DE ENSINO E APRENDIZAGEM}

A didática desenvolvimental tem por missão concretizar na prática processos que levem à consecução dos objetivos da educação, da escola e da pedagogia que a tradição da teoria histórico-cultural sustenta e defende; bem como produzir conhecimento novo no campo investigativo que, em parte, ajude a resolver muitas coisas que ainda faltam ser esclarecidas. 
A didática desenvolvimental, enquanto ciência interdisciplinar, vinculada à Pedagogia, ocupa-se da organização adequada da atividade de ensino-aprendizagem-desenvolvimento, tendo o ensino intencional como seu objeto, a aprendizagem como condição e o desenvolvimento das neoformações e da personalidade integral do estudante, especialmente do pensamento teórico, como objetivo. Em outras palavras, a didática se ocupa do estudo dos princípios mais gerais de organização adequada da atividade de ensino ou instrução, tendo as leis do desenvolvimento mental da criança, as particularidades das idades e as características individuais da aprendizagem como condições desse processo.

Enquanto objeto, o ensino intencional, especificamente, faz referência tanto ao tipo de conteúdo como aos métodos adequados para a formação do pensamento teórico. Davídov, na apresentação da versão para o espanhol de sua obra $O$ ensino escolar e o desenvolvimento psíquico (1988), reconhece que uma nova educação, adequada aos tempos modernos e à revolução científico-técnica contemporânea e que esteja colocada em função do desenvolvimento deve levar em consideração a tarefa de modificar o conteúdo e os métodos de ensino das crianças.

Em relação ao conteúdo, as disciplinas escolares devem introduzir um volume crescente de conhecimentos que correspondam às conquistas da ciência e da cultura. Mas não pode ser qualquer conteúdo e sim uma modalidade especial que permita e potencialize os tipos de atividade cognitiva cuja assimilação influencia de maneira efetiva o desenvolvimento. De acordo com Talizina (2001), só os conteúdos invariantes têm condições de fazer isso. Ela vai afirmar que os conteúdos invariantes são aqueles conhecimentos que constituem a base de muitos conteúdos das matérias escolares e não os conhecimentos particulares que a escola tradicional se esforça em ensinar. Por serem invariantes, esses conteúdos permitem a aquisição de conceitos científicos e ações mentais que podem ser transferidos para novas situações da mesma espécie pelo alto nível de abstração e generalização em que se formam.

Em relação aos métodos, é preciso afirmar que eles, junto com os demais componentes, são responsáveis pelo êxito do processo de ensino-aprendizagem-desenvolvimento. Cabe aos métodos dar direção ao estudo dos alunos de modo a eles alcançarem a assimilação dos conteúdos invariantes. I. Ya. Lerner e M. N. Skatkin (1984) estabelecem um sistema 
de métodos que define a atividade cognitiva que realizam os estudantes; determinam, formulam e estabelecem a estrutura dos métodos de ensino; esquematizam os mesmos com base nos diferentes níveis de assimilação do conteúdo do ensino e elaboram uma classificação que inclui o seguinte sistema de métodos: a) métodos explicativos ilustrativos, b) reprodutivos, c) exposição por problemas, d) busca parcial ou heurística, e) investigativo. Não obstante, ambos autores consideram, dentre todos os métodos, o ensino por problemas (situações-problema) o mais importante de todos os métodos, por ser o que mais potencialidades oferece aos estudantes, guiados pelo professor, introduzirem-se num processo de busca da solução de problemas novos, graças ao qual aprendem a adquirir com independência os conhecimentos, a utilizar os conhecimentos previamente assimilados e a dominar a experiência da atividade criadora.

M. I. Majmutov (1983) também ressalta a importância dos conteúdos e dos métodos no processo de construção de uma didática desenvolvimental. Segundo esse autor, o desenvolvimento intelectual dos estudantes acontece não só pelo volume e qualidade dos conhecimentos adquiridos mas também pela estrutura do processo do pensamento e o sistema de operações lógicas e mentais que dominam. Sobre os métodos de ensino, especificamente, afirma estar convencido de que o ensino baseado em problemas é a via mais eficaz na edificação das bases de um novo tipo de educação cujo objetivo principal é educar as capacidades criadoras de cada estudante e assim formar sua independência cognoscitiva. É esse o motivo pelo qual considera o ensino por problemas o elemento principal do sistema atual de ensino que tende ao desenvolvimento, definindo-o da seguinte forma:

Denominamos problemático o ensino em que os alunos assimilam todo o material docente apenas mediante a solução independente de problemas e o "descobrimento" de novos conceitos. Aqui se encontram também a explicação do professor, a atividade produtiva dos alunos, a formulação de tarefas e a realização de exercícios por parte dos estudantes [...] (MAJMUTOV, 1983, p. 263).

O ensino por problemas nessa perspectiva, diferentemente de outras que enfocam a solução de problemas em uma visão meramente cognitiva (aquisição de estruturas de conhecimento), considera que essa é 
fonte não apenas de assimilação de novos conhecimentos mas também de neoformações e/ou mudanças funcionais no desenvolvimento.

A assimilação de conceitos e de ações mentais, baseado na organização de processos de resolução de problemas selecionados especialmente para tal fim, parte da tese de Vygotsky de que a instrução ou o ensino é fonte do desenvolvimento psíquico, da evolução da conduta, da formação das funções mentais superiores. Segundo citação do próprio Vygotsky (VYGOTSKY, 1956 apud DAVÍDOV, 1988, p. 31), “[...] o ensino é o aspecto internamente essencial e universal no processo de desenvolvimento, na criança, das características humanas diferenciadas que não são naturais mas históricas."

Sobre a base dessa tese, Vygotsky elaborou também o que seria uma de suas maiores contribuições no campo da psicologia escolar sobre uma nova forma de organizar a educação e o ensino modernos: a teoria da zona de desenvolvimento possível. Tal teoria parte da ideia de que não existe apenas uma zona de desenvolvimento na criança, mas duas, a) a área de desenvolvimento efetivo; e b) a zona de desenvolvimento possível. Quanto à primeira, área de desenvolvimento efetivo, expressa o nível de desenvolvimento das capacidades atingido pelo indivíduo num certo estágio de sua vida, manifesta-se na solução independente de tarefas intelectuais e se determina por intermédio de avaliações diagnósticas:

Entendemos por isso o nível de desenvolvimento das funções psicointelectuais da criança que se conseguiu como resultado de um específico processo de desenvolvimento já realizado (VYGOTSKY, 2010, p. 110).

No que diz respeito à segunda, zona de desenvolvimento possível, consiste em que a criança, em certo estágio do seu desenvolvimento, pode desempenhar "sob a orientação de adultos e em cooperação com seus companheiros que sabem mais que ela", ações que não consegue executar sozinha. As tarefas e ações que a criança desempenha inicialmente sob a orientação e em cooperação formam precisamente a "zona" do seu desenvolvimento possível, já que no futuro ela conseguirá desempenhá-las totalmente sozinha.

De acordo com a ideia de Vygostky, pode-se afirmar que o ensino mais adequado é aquele que dirigiido para a zona de desenvolvimento possível, levando em consideração, como ponto de partida, a área de desenvolvimento efetiva ou real, pois, como ele mesmo indica, "[...] o único bom ensino é o que se adianta ao desenvolvimento [...]", "“[... a pedagogia 
não deve orientar-se em direção ao passado mas na direção do futuro (do amanhã), do desenvolvimento da criança [...] "(VYGOTSKY, 2010, p. 114). Enfim: "Os processos de ensino e educação em cada idade não dependem tanto das características presentes, organizadas e maduras da criança, mas daquelas que se encontram em sua zona de desenvolvimento proximal."

"O processo de desenvolvimento não coincide com o da aprendizagem, o processo de desenvolvimento segue o da aprendizagem, que cria a área de desenvolvimento potencial" (VYGOTSKY, 2010, p. 116).

Em síntese, podemos afirmar que a instrução ou o ensino, enquanto objeto da didática, é uma atividade específica que gera desenvolvimento (o ensino precede o desenvolvimento) quando está direcionado para a zona de desenvolvimento potencial ou possível, por intermédio da assimilação, pela via da resolução de problemas (método), dos conteúdos invariantes que estão na base dos conceitos científicos e das ações mentais sobre os quais se produz o pensamento teórico.

Resta explicar como acontece do ponto de vista didático o processo de assimilação dos conhecimentos bem como dos conceitos científicos e ações mentais que levam à formação do pensamento teórico.

De acordo com Leontiev (1978, p. 235), “[...] o desenvolvimento, a formação das funções e faculdades psíquicas próprias do homem enquanto ser social produzem-se sob uma forma absolutamente específica - sob a forma de um processo de apropriação, de aquisição.” As funções psíquicas, especificamente humanas, têm o seu processo de origem e estabelecimento decorrentes da interiorização da atividade externa dos homens, que se transforma em atividade interna mediante a atividade desse sujeito nas suas interações com os outros homens e com a natureza.

Dessa maneira, nas relações que se estabelecem em diferentes contextos sociais, o homem se apropria dos conhecimentos acumulados anteriormente pelas gerações que o precederam, não somente os científicos (elaborados com base em teorias) até o momento destacados, mas também cotidianos (construídos e adquiridos empiricamente). Esses últimos, conceitos espontâneos ou cotidianos, são aprendidos pela experiência sensorial, apoiam-se na observação, na representação e surgem como resultado de dois tipos de abstrações diferentes; a primeira, a partir de generalizações e classificações que têm como base os aspectos aparentes e, portanto, não essenciais dos objetos ou fenômenos; a segunda, aquelas que levam em 
consideração todos ou alguns dos elementos essenciais que caracterizam o objeto, bem como as relações que se dão na estrutura de sua definição, mas sem tomar consciência disso. O conhecimento empírico é a vida do próprio homem (HELLER, 2004) e, portanto, é por ele apropriado nas relações sociais que estabelece nos contextos culturais onde vive. Os científicos, por sua vez, incluem a observação, mas apoiam-se sobretudo na ação cognoscitiva que descobre as conexões internas, essenciais e contraditórias como fonte dos fenômenos observados e são parte de um sistema complexo de inter-relações conscientes, expressos em princípios, leis e generalizações. Encontram-se nas esferas não cotidianas (HELLER, 2004) da vida (nas ciências, artes etc.) e são apropriados na escola (tal como entendida sob as bases teóricas da psicologia histórico-cultural).

Para Davídov (1988), o limite entre os conceitos espontâneos e científicos não passa pela linha de "admitir" o objeto dado tal e como ele é em si mesmo, ou na conexão observada com outros objetos, mas pela linha de esclarecer as causas internas e as condições de sua origem. Entre ambos conceitos não há uma relação linear, mas sim uma unidade dialética, na qual os cotidianos são base para os científicos. Seja num ou noutro âmbito, o homem passa da consciência social para a individual. Dessa forma,

[...] a sua consciência individual só pode existir nas condições de uma consciência social; é apropriando-se da realidade que o homem a reflete como através do prisma das significações, dos conhecimentos e das significações elaboradas socialmente [...] (LEONTIEV, 1978, p. 130).

Se a individualidade (a pessoalidade - intrapsicológico) constitui-se sob a base da genericidade (o genérico produzido histórico e culturalmente - interpsicológico), essa relação é definidora dos traços daí decorrentes. Ou seja, se a genericidade for em si (cotidiana), constituirá uma individualidade em si; se a genericidade for para si (científica), a individualidade também o será.

$\mathrm{Na}$ escola desenvolvimental intenciona-se a constituição de individualidades para si (sob a óptica do desenvolvimento do pensamento teórico), deslocando a atenção do aluno da relação signo-objeto (característica da constituição do pensamento empírico) para a relação signo-signo (característica do pensamento abstrato). 
Do ponto de vista didático, para a formação do pensamento teórico os conceitos precisam ser assimilados pela via das condições de sua origem, pois não se transmitem enquanto conhecimento pronto (NÚÑEZ, 2009). Talizina (2001) reconhece que os conceitos não podem ser transferidos aos alunos em forma acabada, eles mesmos devem obtê-los interagindo com os objetos relacionados a esses conceitos, os quais se encontram na sociedade na forma de cultura. O processo de assimilação desse sistema sempre se dá com ajuda dos adultos agindo na zona de desenvolvimento possível, com base na resolução de problemas de complexidade adequada à capacidade dos estudantes.

Uma das contribuições mais importantes sobre a teoria da assimilação deve-se a Leontiev (1974). Ele desenvolveu várias das proposições de Vygotsky a esse respeito. Segundo Leontiev, o indivíduo se apropria das conquistas das gerações passadas

[...] para se apropriar dos objetos ou dos fenômenos que são o produto do desenvolvimento histórico, é necessário desenvolver em relação a eles uma atividade que reproduza, pela sua forma, os traços essenciais da atividade encarnada, acumulada no objeto. [...] o homem não nasce dotado das aquisições históricas da humanidade. Resultando estas do desenvolvimento das gerações humanas, não são incorporadas nem nele, nem nas suas disposições naturais, mas no mundo que o rodeia, nas grandes obras da cultura humana. Só apropriando-se delas no decurso da sua vida ele adquire propriedades e faculdades verdadeiramente humanas. Este processo coloca-o, por assim dizer, nos ombros das gerações anteriores e eleva-o muito acima do mundo animal [...] (LEONTIEV, 1978, p. $268,282-283)$.

Seu conceito mais geral de apropriação (prisvoenie) expressa as relações essenciais entre a experiência individual e a experiência social e constitui o processo que "leva o indivíduo à reprodução, em sua própria atividade, das capacidades humanas formadas historicamente" (DAVÍDOV, 1988, p. 31). O próprio Leontiev (1974, p. 177) vai afirmar:

[...] esse mundo objetivo que encarna as atitudes humanas formadas no processo de desenvolvimento da prática sócio-histórica não se dá ao indivíduo nessa qualidade desde o início. Para que essa qualidade, esse aspecto humano dos objetos circundantes se descubra ao indivíduo, ele deve realizar uma atividade relacionada com eles, atividade adequada (ainda que não idêntica) àquela que eles têm cristalizada em si. 
Assimilar, reproduzir, interiorizar e internalizar são termos que, dentro da teoria histórico-cultural, têm o mesmo significado e podem ser entendidos como sinônimo de aprender ou aprendizagem ${ }^{2}$. Todos eles definem a capacidade humana de transformar a experiência social em experiência individual (o passo do interpsicológico ao intrapsicológico). Para Galperin (2001), aprender significa: "Toda atividade cujo resultado é a formação de novos conhecimentos e habilidades em quem a executa, a incorporação de novas qualidades aos conhecimentos e habilidades que já se possui $[\ldots . .$. " (p. 85).

Assimilar ou aprender exige do aluno a realização na escola de um tipo específico de atividade de apropriação dos conceitos científicos e das ações mentais num processo similar, mas não idêntico, ao que a sociedade precisou efetuar para produzir esses conceitos. Em outras palavras, o estudante desenvolve o pensamento teórico aprendendo conceitos e ações no processo de formação e constituição de sua ontogênese pela reprodução do processo de formação da filogênese da sociedade, só que no sentido contrário. A sociedade produz a sua filogênese indo do concreto para o abstrato, enquanto que o estudante produz sua ontogênese indo do abstrato para o concreto. Isso só pode ser feito porque os conceitos dos quais os alunos se apropriam estão prontos na sociedade e só pode ser feito na escola porque exige condições didáticas especiais relacionadas aos conteúdos, bem como às formas (métodos) de sua apropriação.

Por isso, do ponto de vista didático, é necessário o confronto dos saberes, o que na lógica dialética significa a luta dos contrários, a negação da negação. Sob a base do materialismo histórico-dialético, todo elemento contém em si o seu contrário e é da luta entre eles que emerge sua síntese. No campo do desenvolvimento do pensamento, podemos dizer que se tem como ponto de partida o concreto, como contraponto o abstrato e como síntese o concreto pensado, a praxis.

A aprendizagem na teoria marxista pressupõe, pois, que se choquem tipos de conhecimentos contraditórios a partir dos quais sejam possíveis novas elaborações, processos de aquisição de conhecimentos que modificam as formas de pensamento e possibilitam novas formações psíquicas (o desenvolvimento). Nessa perspectiva, o ponto de partida é o pensamento empírico, a realidade, a prática social do sujeito, tendo como base o conhecimento cotidiano que o homem tem do mundo objetivo. Contudo, 
é preciso confrontar, a esse saber, um tipo particular de conhecimento que se constitui a partir das elaborações científicas, de caráter teórico, o conhecimento científico. Ambos conhecimentos são socialmente construídos, mas com lógicas distintas. Esses dois tipos particulares de conhecimentos precisam ser confrontados para que o estudante possa desenvolver processos psíquicos a partir dos quais compreenda e aja sobre a realidade objetiva operando teórico-conceitualmente.

Há, pois, uma relação direta entre o tipo de pensamento que se desenvolve e a atividade desenvolvida pelo homem, o que o coloca numa condição de sujeito direto de seu processo de constituição humana, reprodutor e produtor do patrimônio cultural que assim o caracteriza.

No contexto didático-pedagógico da escola desenvolvimental, ENSINO-APRENDIZAGEM-DESENVOLVIMENTO se constituem unitária e dialeticamente como processo ativo no qual professores e alunos, sujeitos desse processo, encontram-se na condição de atividade, entendida como conceito chave na tradição da teoria histórico-cultural para explicar a relação homem-natureza. "A categoria filosófica da atividade é a abstração teórica de toda a prática humana que tem um caráter histórico-social [...]" (DAVÍDOV, 1988, p. 15).

A atividade, desenvolvida de forma sistemática por Leontiev ${ }^{3}$, é o processo no qual a realidade é transformada pelos esforços criativos dos homens e no qual o trabalho é a forma original dessa transformação. Os principais componentes da atividade são: necessidades, motivos, metas, condições, meios, ações e operações. A atividade tem como condição primeira a necessidade e pressupõe a coincidência entre o motivo da ação e seu objetivo. Assim, no contexto do processo educativo, as atividades de ensino e de aprendizagem precisam estar articuladas por uma necessidade comum, enquanto o motivo dessas ações (aquilo que move os sujeitos nesse processo) precisa coincidir com suas finalidades. A atividade consiste, portanto, num conjunto de ações articulas entre si por objetivos comuns que potencializam o desenvolvimento da psique e da personalidade humana, isto é, o desenvolvimento integral do homem.

Entendamos melhor: a atividade somente se constitui como tal se partir de uma necessidade. A necessidade é sua condição primeira, sua condutora, mas ela, por si mesma, não é capaz de provocar a atividade. Para tanto, ela deve encontrar um objeto que lhe seja correspondente. Objetos 
e necessidades isolados não produzem a atividade, esta se realiza somente quando se tem um motivo. $\mathrm{O}$ encontro entre a necessidade e o objeto denomina-se motivo e o que diferencia uma atividade de outra é o seu objeto, isto é, seu motivo; ambos precisam coincidir para que permaneçam na condição de atividade.

Sempre que o motivo que impele o indivíduo a agir coincidir com o que ele faz, ou melhor, com o conteúdo da ação, com a função do objeto, é considerada uma atividade. Quando o motivo [...] não coincidir com o objetivo visado, trata-se de uma ação [...] (FRANCO; LONGAREZI, 2011, p. 577).

Assim, quando essa coincidência não ocorre, quando o que move o sujeito não corresponde ao seu objetivo, não se tem atividade, mas sim ação. A ação é "[...] um processo cujo motivo não coincide com o seu objetivo [...], mas reside na atividade da qual ela faz parte [...]" (LEONTIEV, 2001, p. 69). Isto é, a ação carece de um motivo que a impulsione, em vez disso, ela possui um objetivo que a direciona. Nas palavras de Leontiev (2001, p 69), “[...] para que uma ação surja e seja executada é necessário que o seu objetivo apareça para o sujeito em sua relação com o motivo da atividade da qual ele faz parte". Embora a ação sempre esteja relacionada com o motivo da atividade, uma vez que elas somente se realizam dentro desse processo, são portadoras de uma relativa autonomia frente às atividades, podendo compor e se fazer presente em várias delas.

Uma atividade corresponde, portanto, a um conjunto de ações articuladas entre si por um objetivo comum. Para cada ação há uma operação correspondente. As operações são o conteúdo necessário de qualquer ação, "[...] por operações entendemos o modo de execução de um ato [...]" (LEONTIEV, 2001, p. 74).

O que distingue operações de ações é que “[...] uma operação depende das condições em que o alvo da ação é dado, enquanto uma ação é determinada pelo alvo [...]" (Id., 2001, p. 74).Dessa forma, uma mesma operação pode compor ações distintas ou uma mesma ação ser realizada mediante diferentes operações.

Para Leontiev (2001, p. 76), no ensino de matemática, por exemplo, “[...] a ação mental [...] deve tornar-se [...] a solução de um problema e não uma simples soma; a soma torna-se operação e deve, por isso, adquirir a forma de hábito automático adequadamente desenvolvido [...]" (LEONTIEV, 2001, p. 76). 


\section{Quando}

[...] o nível do desenvolvimento das operações é suficientemente alto, torna-se possível passar para a execução de ações mais complicadas e estas, por sua vez, podem proporcionar a base para novas operações que preparam a possibilidade para novas ações, e assim por diante [...] (LEONTIEV, 2001, p. 2001).

Cabe salientar que, em sua estrutura, os componentes da atividade não são estáticos, podem se modificar, adquirindo diferentes funções. Se em uma atividade objeto e motivo deixam de coincidir, ela torna-se uma ação e vice-versa. Nesse mesmo sentido, se as ações se tornam apenas um meio para alcançar um objetivo, constituem-se em operações.

De modo geral, os componentes da atividade podem ser definidos da seguinte forma: "[...] a atividade é dirigida por motivos; as ações são orientadas por objetivos; e as operações são reguladas por condições [...]” (LONGAREZI; ARAUJO; FERREIRA, 2007, p. 71). Contudo,

- Para que uma ação tenha significado para o sujeito é necessário que ela seja produzida por um motivo;

- Para que as ações passem para um lugar inferior na estrutura da atividade, tornando-se operações, é preciso que novas necessidades ou motivos exijam ações mais complexas;

- Para que, subjetivamente, o sujeito sinta novas necessidades ou motivos que o estimulem a agir em um nível superior, é preciso que esteja inserido em um contexto que produza, objetivamente, a necessidade de novas ações; e

- Para que uma operação seja automatizada de forma consciente, é necessário que ela se estruture inicialmente na condição de ação (SFORNI, 2006, p. 4-5).

Pelo exposto fica evidente que "[...] a atividade é uma forma complexa de relação homem-mundo que envolve finalidades conscientes e atuação coletiva e cooperativa [...]" (OLIVEIRA, 1998, p. 98).

A atividade vista no contexto educativo, mais especificamente no contexto da escola, configura-se enquanto atividade de ensino e atividade de aprendizagem. A primeira, objeto do trabalho docente, condiciona e cria as bases da segunda, objeto da atividade do aluno. Enquanto unidade formadora, Moura (2010) a denomina Atividade Orientadora de Ensino (AOE), na qual as duas, em sua interdependência, promovem a formação e 
o desenvolvimento de ambos sujeitos do processo de ensino-aprendizagemdesenvolvimento: professores e alunos.

Esse tipo de atividade também supõe que haja uma necessidade, bem como ações a ela articuladas, orientadas por operações que, por sua vez, são definidas pelas condições; e, sobretudo, demanda que o motivo que mobiliza o professor coincida com o objeto de sua ação, seu alvo. Sob esse aspecto, a atividade de aprendizagem do aluno se situa como uma particularidade importante a ser considerada na atividade de ensino, por isso estão estritamente ligadas.

A atividade de ensino do professor deve gerar e promover a atividade do estudante. Ela deve criar nele um motivo especial para a sua atividade: estudar e aprender teoricamente sobre sua realidade. É com essa intenção que o professor planeja a sua própria atividade e suas ações de orientação, organização e avaliação [...] (MOURA et al., 2010, p. 90).

Se isso ocorre de maneira consciente e intencional, atividade de ensino e atividade de aprendizagem coincidem enquanto processos que desenvolvem professores e alunos, possibilitando a ambos, cada qual com sua função social, um na condição do trabalhar e o outro na de estudar, desenvolver novas formações psíquicas, com características e naturezas distintas, mas todas potencializadoras do desenvolvimento humano,

[...] considerando que a formação do pensamento teórico e da conduta cultual só é possível como resultado da própria atividade do homem, decorre que tão importante quanto a atividade de ensino do professor é a atividade de aprendizagem que o estudante desenvolve [...] (MOURA et al., 2010, p. 90).

A atividade de aprendizagem tem um papel determinante como condição para a formação de conceitos. A atividade conceitual na criança não surge porque ela domina o conceito, pelo contrário, domina o conceito porque aprende a agir conceitualmente. Sob essa óptica, a aprendizagem se realiza mediante a apropriação da experiência acumulada.

Assim, pois, o conteúdo principal da atividade de estudo é a assimilação dos procedimentos generalizados de ação na esfera dos conceitos científicos e mudanças qualificadas no desenvolvimento psíquico da criança, que ocorrem sobre essa base [...] (DAVÍDOV, 1987, p. 324). 
O desenvolvimento da consciência, na perspectiva aqui em discussão, não é determinado pelo conceito, mas pela atividade real que relaciona o sujeito à realidade. Assim, a atividade de aprendizagem se manifesta nas ações de aprender, pois "[...] a assimilação do conteúdo é um tipo de atividade. Para que o aluno aprenda é preciso que ele realize determinadas ações [...]" (NÚÑEZ, 2009, p. 71). Sob esse enfoque, a atividade só agirá como tal se satisfizer suas necessidades.

No contexto da atividade, a aprendizagem é o processo exclusivamente humano pelo qual o indivíduo assimila, internaliza e reproduz a experiência humana (cultura) elaborada pelas gerações precedentes. Nesse sentido, os processos de aprendizagem permitem a cada indivíduo fazer sua a cultura, a partir do domínio dos objetos e seus usos, bem como dos modos de atuar, de pensar e de sentir e das formas de aprender vigentes em cada contexto histórico. Isto é, ao apropriar-se dos conteúdos culturais, as pessoas se apropriam também das formas, dos métodos e dos meios de pensar esses objetos comuns a um tipo específico de sociedade.

A partir dessa concepção, a aprendizagem desempenha um importante papel porque age como embasamento indispensável para a produção de processos de desenvolvimento e, simultaneamente, para que os níveis de desenvolvimento alcançados abram caminho para novas aprendizagens.

Nessa perspectiva, a didática desenvolvimental tem por finalidade criar as condições objetivas e subjetivas de colocar os sujeitos em atividade de ensino-aprendizagem-desenvolvimento, de tal modo que seja possível a apropriação de conhecimentos científicos como objetivo-meio, para que o pensamento teórico seja desenvolvido como objetivo-fim. Esse processo se realiza enquanto unidade apropriação-objetivação, pois se intenciona não apenas a internalização dos conhecimentos mas a mudança na forma de pensamento, de modo que o sujeito se relacione teoricamente com a realidade, pense e aja conceitualmente, portanto, desenvolva ações mentais importantes para um novo olhar e uma nova ação sobre o mundo objetivo.

Dessa maneira, mudam não somente as capacidades de abstração, mas as formas ativas de pensamento. Portanto, na unidade objetivaçãoapropriação, o homem se apropria e produz formas humanas de inserção no mundo cultural e historicamente produzido. 
Didadicamente trata-se, então, de um processo em que a atividade psíquica do estudante precisa ser mobilizada pelos processos mediacionais selecionados pela atividade de ensino para que ele, na atividade de aprendizagem, desenvolva as capacidades psíquicas acima relacionadas. Sob esse aspecto, Galperin sinaliza para um princípio extremamente relevante: o mais importante não é o conteúdo da ação, mas o processo de assimilação do conteúdo, pois esse é o real conteúdo das neoformações psíquicas, é o processo de assimilação que desencadeará situações formativas com força de formação e transformação das capacidades e habilidades mentais. Por isso, a atividade do sujeito é fundamental nas condições apresentadas.

Sob essa óptica, o trabalho do professor pressupõe a identificação das necessidades preliminares dos estudantes e a criação das necessidades comuns ao coletivo de estudantes, de modo que os motivos sejam educados, fazendo coincidir o que move as ações individuais e coletivas no contexto educativo e o objeto a que elas se dirigem (o ensino-aprendizagem-desenvolvimento); implica, ainda, a criação e organização das condições objetivas e subjetivas para a elaboração e o desenvolvimento de atividades de ensino e atividades de aprendizagem, enquanto unidades formativas e formadoras.

Assim compreendidos, os conceitos aqui desenvolvidos constituem, em seu conjunto, o constructo teórico que fundamenta uma prática educativa na qual à didática desenvolvimental delega-se o ensino intencional como seu objeto, a aprendizagem como condição e o desenvolvimento das neoformações e da personalidade integral do estudante como objetivo. Sob esse enfoque, depreende-se, pois, que a didática se projeta e se efetiva na relação indissociável ensino-aprendizagem-desenvolvimento. 


\section{REFERÊNCIAS}

DAVÍDOV, V. Análisis de los principios didácticos de la escuela tradicional y posibles principios de enseñanza en el futuro próximo. In: SHUARE, M. La psicología evolutiva y pedagógica en la URSS: Antología. Moscú: Progreso, 1987.

DAVÍDOV, V. La Enseñanza Escolar y el Desarrollo Psíquico. Moscú: Editorial Progreso, 1988. FRANCO, P. P. J.; LONGAREZI, A. M. Elementos constituintes e constituidores da formação continuada de professores: contribuições da Teoria da Atividade. Revista Educação e Filosofia, Uberlândia, v. 25, n. 50, p. 557-582, jul./dez. 2011.

GALPERIN, P. Y. Sobre la formación de los conceptos y de las acciones mentales: La ciencia psicológica en la URSS. T.I. 1959. 2. reimpr. In: ROJA, L. Q. (Comp.). La formación de las funciones psicológicas durante el desarrollo del niño. 2001.

HELLER, A. Estrutura da vida cotidiana. Rio de Janeiro: Paz e Terra, 2004.

LEONTIEV, A. N. Problemas del desarrollo del psiquismo. 2. ed. La Habana: Editorial Pueblo y Educación, 1974.

LEONTIEV, A. N. Actividad, consciência e personalidad. Buenos Aires: Ciências del Hombre, 1983. LEONTIEV, A. N. Imagem do mundo. In. GOLDER, M. Leontiev e a psicologia histórico-cultural: um homem em seu tempo. São Paulo: Grupo de Estudos e Pesquisa sobre Atividade Pedagógica: Xamã, 2004. p. 48-63.

LEONTIEV, A. N. Uma contribuição à teoria do desenvolvimento da psique infantil. In: VYGOTSKY, L.; LURIA, A. R.; LEONTIEV, A. N. Linguagem, desenvolvimento e aprendizagem. São Paulo: Ícone, 2001.

LEONTIEV, A. O desenvolvimento do psiquismo. Lisboa: Horizonte, 1978.

LERNER, I. Y.; SKATKIN, M. N. Métodos de enseñanza. In: DANILOV, M. A.; SKATKIN, M. N. Didáctica de la Escuela Media. 2. reimpr. La Habana: Editorial Pueblo y Educación, 1984. p. 176-223.

LONGAREZI, A. M.; ARAUJO, E. S.; FERREIRA, S. A psicologia histórico-cultural na formação do profissional docente. Revista Série Estudos, Campo Grande, p. 65-78, jan./ jun. 2007.

MAJMUTOV, M. I. La enseñanza problémica. La Habana: Editorial Pueblo y Educación, 1983. MOURA, M. O. et al. Atividade Orientadora de Ensino como unidade entre ensino e aprendizagem. In: MOURA, M. O. (Org.). A atividade pedagógica na teoria histórico-cultural. Brasília: Liber livro, 2010. p. 81-110.

NÚÑEZ, I. B. Vygosky, Leontiev e Galperin: formação de conceitos e princípios didáticos. Brasília: Liber Livro, 2009.

OLIVEIRA, Marta Kohl de. Vygotsky aprendizado e desenvolvimento um processo sócio-histórico. 4.ed. São Paulo: Scipione, 1998.

PETROVSKI, A. Psicología General: Manual didáctico para los Institutos de Pedagogía. 3. ed. Moscú: Editorial Progreso, 1986.

SFORNI, M. S. F. Aprendizagem conceitual e apropriação da linguagem escrita: um diálogo necessário. In: REUNIÃO ANUAL DA ANPED - EDUCAÇÃO, CULTURA E CONHECIMENTO NA CONTEMPORANEIDADE, 29, 2006, Caxambu. Anais.... Caxambu, 2006. p. 1-13. 
TALIZINA, N. F. Introducción. In: TALIZINA, N. F. La formación de las habilidades del pensamiento matemático. San Luís Potosi: Facultad de Psicología de la Universidad Autónoma de San Luís Potosi, 2001. p. 9-20.

TALIZINA, N. F. Manual de Psicología Pedagógica. San Luís Potosi: Facultad de Psicología de la Universidad Autónoma de San Luís Potosi, 2000.

VYGOTSKY, L. S. Investigaciones psicológicas escogidas. Moscú: Editorial de la ACP de la RSFSR, 1956.

VYGOTSKY, L. S. Aprendizagem e desenvolvimento intelectual na idade escolar. In: VYGOTSKY, L. S.; LURIA, A. R.; LEONTIEV, A. N. Linguagem, desenvolvimento e aprendizagem. 10. ed. São Paulo: Ícone, 2010. p. 103-118.

\section{NOTAS}

${ }^{1} \mathrm{O}$ texto apresenta dados de pesquisas financiadas pelo CNPq e pela FAPEMIG.

${ }^{2}$ Segundo Prestes (2010), não há na língua russa um termo correspondente para aprendizagem, pelo que considera inadequado o uso da palavra obutchenie. Por sua vez, a russa Yulia Solovieva, naturalizada mexicana, doutora em Psicologia Pedagógica pela Universidade de Moscou (1993), pós-doutora em Neuropsicologia (Sevilha, Espanha, 1999), colaboradora de Nina Talizina durante uma década e tradutora, afirma que a tradução da palavra aprendizagem para o russo é ucheniye ou obutchenie. O tradutor DEVE tomar a decisão a respeito. A palavra obucheniye também pode significar ensino, pelo que o termo obutchenie inclui tanto ensino quanto aprendizagem.

${ }^{3}$ Leontiev (2001, p. 68) designa por atividade "os processos psicologicamente caracterizados por aquilo a que o processo, como um todo, se dirige (seu objeto), coincidindo sempre com o objetivo que estimula o sujeito a executar esta atividade, isto é, o motivo".

Recebido: $28 / 02 / 2012$

Aprovado: 28/09/2012

Contato:
Universidade Federal de Uberlândia
Faculdade de Educação
Rua Planalto 120, apto 402, Bloco B
Bairro Santa Mônica
CEP 38408-064
Uberlândia, MG
Brasil

